\title{
Desinfecção das mudas com óleo de eucalipto na produção e controle de doenças da mandioquinha-salsa
}

\section{Disinfection of cuttings with eucalyptus oil on yield and disease control of Peruvian carrot}

\author{
Maria do Carmo Vieira ${ }^{*}$; Kátia Regina Freitas Schwan-Estrada ${ }^{2}$; Néstor Antonio \\ Heredia Zárate ${ }^{3}$; Noemi Pelisson ${ }^{4}$; Cleila Marcondes de Souza Sangalli ${ }^{5}$; Maria \\ Fernanda dos Santos Paula ${ }^{6}$
}

\begin{abstract}
Resumo
O objetivo do trabalho foi estudar o efeito de doses e tempos de imersão em óleo de eucalipto (Eucalyptus globulus Labill.), utilizado na desinfecção das mudas, na produção e no controle de doenças da mandioquinha-salsa 'Amarela de Carandaí'. Foram avaliados nove tratamentos $(0,45 \% / 18$ "; 1,05\%/18"; 0,45\%/42"; 1,05\%/42"; 0,75\%/30"; 0,075\%/18"; 1,425\%/42"; 0,45\%/3" e 1,05\%/57”), no delineamento experimental de blocos casualizados, com quatro repetições. As mudas (rebentos) foram selecionadas, imersas nas soluções conforme os tratamentos e deixadas para secar. No dia do plantio, os rebentos foram cortados horizontalmente na parte basal e colocados no fundo dos sulcos, com o ápice para cima. A colheita foi realizada aos 229 dias após o plantio. Os maiores estandes iniciais e finais foram sob as doses de óleo menores que 1,0\% e tempos de imersão variando entre 3" e 42 ". A interação dose de óleo de eucalipto e tempo de imersão das mudas influenciaram significativamente as produções de massa fresca de folhas $\left(2,49 \mathrm{t} \mathrm{ha}^{-1}\right.$, sob $0,30 \% / 0,02$ "), rebentos $\left(2,32 \mathrm{t} \mathrm{ha}^{-1}\right.$, sob $0,38 \% / 33,26$ ") e raiz comercial $\left(3,32 \mathrm{t} \mathrm{ha}^{-1}\right.$, sob $0,44 \% / 39,21$ " $)$ e as massas secas de coroa $\left(0,38 \mathrm{t} \mathrm{ha}^{-1}\right.$, sob $\left.0,76 \% / 36,57^{\prime \prime}\right)$ e de raiz comercial $\left(0,65 \mathrm{t} \mathrm{ha}^{-1}\right.$, sob $0,20 \% / 17,9$ "). As mudas de mandioquinha-salsa devem ser desinfectadas com óleo de eucalipto em doses menores que $0,5 \%$ e com imersão na solução em torno de 40 ", para obter-se menor incidência e severidade de doenças foliares e maior produção de raízes comerciais.

Palavras-chave: Arracacia xanthorrhiza. Eucalyptus globulus. Controle alternativo de doenças. Produtividade.
\end{abstract}

\begin{abstract}
The aim of this work was to study the effect of eucalyptus oil (Eucalyptus globulus Labill.) which was used in disinfection of cuttings in different doses and periods of immersion, on yield and disease control of "Amarela de Carandaí' Peruvian carrot. Nine treatments ( $0.45 \% / 18$ "; $1.05 \% / 18$ "; $0.45 \% / 42$ "; $1.05 \% / 42 " ; 0.75 \% / 30 " ; 0.075 \% / 18 " ; 1.425 \% / 42 " ; 0.45 \% / 3 "$ and $1.05 \% / 57 ")$ were evaluated in
\end{abstract}

\footnotetext{
1 Prof. Titular e Bolsista de Produtividade em Pesquisa do CNPq. Universidade Federal da Grande Dourados, Faculdade de Ciências Agrárias, C. Postal 533, 79804-970, Dourados, MS. E-mail: vieiracm@terra.com.br

2 Eng $^{\mathrm{o}}$ Agr $^{\circ}$, DSc., Professor Associado C do Centro de Ciências Agrárias, Universidade Estadual de Maringá, UEM, Av. Colombo, 5790, Universitário, 87020-900 - Maringá, PR. E-mail: krfsestrada@uem.br

3 Prof. Associado 3 e Bolsista de Produtividade em Pesquisa do CNPq. Universidade Federal da Grande Dourados, Faculdade de Ciências Agrárias, C. Postal 533, 79804-970 - Dourados-MS. E-mail: nahz@terra.com.br

4 Eng $^{\mathrm{o}}$ Agr $^{\mathrm{o}}$, Pós-graduando do curso de Mestrado em Genética e Melhoramento, Universidade Estadual de Maringá, UEM. E-mail: npelisson@gmail.com

${ }^{5}$ Bacharel em Ciências Biológicas, Pós-graduando do curso de Mestrado em Agronomia, Universidade Federal da Grande Dourados, C. Postal 533, 79804-970 Dourados, MS. Bolsista da FUNDECT. E-mail: cleilamar8@yahoo.com.br

6 Estudante de Graduação do Curso de Agronomia, Universidade Federal da Grande Dourados, C. Postal 533, 79804-970 Dourados-MS, Aluna Voluntária em Pesquisa. E-mail: fer_santospaula @hotmail.com.

* Autor para correspondência
} 
randomized block experimental design, with four replications. Before planting, cuttings (shoots) were selected, immersed in solutions as treatments and left to dry. The adherence of the oil was better using spreader-sticker. On planting day, shoots were cut horizontally at basal part and put at the bottom of the furrows, with their apices to upside. Harvest was done on 229 days after planting. The greatest initial and final stations were under doses of oil that were smaller than $1.0 \%$ and under periods of immersion that varied between 3" and 42". Dose of eucalyptus and period of immersion of cuttings interaction influenced significantly yields of fresh mass of leaves $\left(2.49 \mathrm{t} \mathrm{ha}^{-1}\right.$, under $0.30 / 0.02$ "), shoots $(2.32 \mathrm{t}$ ha $^{-1}$, under $0.38 \% / 33.26$ ") and commercial root (3.32 $\mathrm{t} \mathrm{ha}^{-1}$, under $0.44 \% / 39.21$ ") and dried masses of crowns (0.38 tha-1, under $0.76 / 36.57$ ') and of commercial root ( $0.65 \mathrm{t} \mathrm{ha}^{-1}$, under $0.20 \% / 17.9$ ”). It was concluded that Peruvian carrot cuttings must be disinfected with eucalyptus oil in doses smaller than $0.5 \%$ and with immersion around 40 ", in order to obtain the smallest incidence and severity of foliar diseases and the greatest yield of commercial roots.

Key words: Arracacia xanthorrhiza. Eucalyptus globules. Alternative control of diseases. Productivity.

\section{Introdução}

Amandioquinha-salsa(Arracaciaxanthorrhiza Bancroft) é uma hortaliça alternativa, nãoconvencional, com plantas rústicas, que pode ser cultivada o ano todo e cujo produto mais valioso são as raízes tuberosas. Embora seja uma hortaliça de propriedades gastronômicas, nutricionais e medicinais importantes, a quantidade disponível nos mercados locais de Mato Grosso do Sul é pequena, por falta de tradição no consumo pela população, fazendo com que essa hortaliça seja oferecida ao consumidor com preços altos e que impedem seu uso nos cardápios de pessoas de baixa renda (HEREDIA ZÁRATE et al., 2008).

A multiplicação da mandioquinha-salsa para fins comerciais é feita, exclusivamente, pelo processo vegetativo, utilizando-se rebentos ou mudas, produzidos na parte aérea da planta, os quais variam em comprimento e diâmetro em função do clone e da idade da planta. A capacidade de uma planta de mandioquinha-salsa produzir bem depende, principalmente, da qualidade do material de plantio que determina diferenças na velocidade de enraizamento, crescimento e, consequentemente, na produção e duração do ciclo vegetativo (HEREDIA ZÁRATE et al., 2009).

No cultivo da mandioquinha-salsa, perdas economicamente significativas podem ocorrer quando não são tomados cuidados básicos de manejo da cultura, dentre eles, os mais críticos são o cultivo repetido no mesmo terreno, utilização de mudas de má qualidade, cultivo em condições climáticas muito desfavoráveis, preparo do solo/ adubação inadequados e irrigação feita sem controle, principalmente com excesso de água (LOPES; HENZ, 1997).

A procura por novos agentes antimicrobianos, a partir de plantas, é intensa devido à crescente resistência dos micro-organismos patogênicos aos produtos sintéticos. Frente a esse problema, uma estratégia atual da agricultura vem sendo a busca de métodos alternativos para o controle de doenças e pragas, que diminuem os danos ao ambiente e à saúde humana. Trabalhos desenvolvidos com extratos brutos ou óleos essenciais, obtidos a partir de plantas medicinais, têm indicado o potencial destes no controle de fitopatógenos (AMARAL; BARA, 2005).

Segundo Vieira, Heredia Zárate e Gomes (2002), vários autores relatam que um dos fatores que tem limitado a expansão da cultura de mandioquinha-salsa é a falta de material de plantio e, por isso, é recomendado o bom aproveitamento das mudas. A importância de se conhecer bem o tipo, o tamanho e a forma como a muda deve ser plantada está principalmente no fato de o ciclo da cultura ser longo e, portanto, ser necessário estabelecer o mais rápido a população final desejada. 
Sobre o tratamento das mudas, há poucas informações, embora um dos problemas de cultivo mais frequentes seja o baixo estande final, em relação ao número de mudas plantadas, causado, muitas vezes, pelo ataque de patógenos comuns em plantios comerciais, como Rhizopus sp. e Erwinia sp. (BRUNE et al., 1996). Para prevenção de doenças e nematóides, Granate, Sediyama e Casali (2007) recomendam a imersão das mudas em solução de hipoclorito de sódio (água sanitária) em água, na proporção de 1:9, durante cinco a dez minutos.

Segundo Schwan-Estrada, Stangarlin e Cruz (2000), trabalhos desenvolvidos com extrato bruto ou óleo essencial, obtido a partir de plantas medicinais, têm indicado o potencial destas substâncias no controle de fitopatógenos, tanto por sua ação fungitóxica direta, inibindo o crescimento micelial e a germinação de esporos, quanto pela indução de fitoalexinas, indicando a presença de composto(s) com características de elicitor(es). Uma grande quantidade de compostos secundários das plantas medicinais já isolados e com estrutura química determinada ainda não foram estudados quanto às suas atividades biológicas. Existem diversas teorias sobre a função dos óleos essenciais dos eucaliptos, mas poucos fatos caracterizam seu papel ecológico e fisiológico. Estes já foram considerados como repelentes de insetos que se alimentam de suas folhas, inibidores da germinação e de crescimento de outras plantas, controladores da atividade microbiológica de alguns fungos e bactérias, entre outros (SALGADO et al., 2003).

Em função do exposto, o objetivo deste trabalho foi estudar o efeito do óleo de eucalipto (Eucalyptus globulus) utilizado na desinfecção de mudas, em diferentes concentrações e tempos de imersão, sobre a produção e o controle de doenças da mandioquinha-salsa.

\section{Material e Métodos}

O trabalho experimental foi desenvolvido na Faculdade de Ciências Agrárias da Universidade Federal da Grande Dourados - UFGD, em Dourados, entre 06/06/2008 e 22/01/2009, em solo do tipo Latossolo Vermelho distroférrico, textura muito argilosa (EMBRAPA, 1999).

Os tratamentos testados resultaram das combinações entre doses de óleo de eucalipto e tempos de imersão das mudas, respectivamente: $0,45 \% / 18 \mathrm{~s} ; 1,05 \% / 18 \mathrm{~s} ; 0,45 \% / 42 \mathrm{~s} ; 1,05 \% / 42 \mathrm{~s}$; $0,75 \% / 30 \mathrm{~s} ; 0,075 \% / 18 \mathrm{~s} ; 1,425 \% / 42 \mathrm{~s} ; 0,45 \% / 3$ $\mathrm{s}$ e $1,05 \% / 57 \mathrm{~s}$, determinados utilizando-se a matriz experimental Plan Puebla III (TURRENT; LAIRD, 1975), conforme o esquema apresentado na Figura 1. O delineamento experimental utilizado foi de blocos casualizados, com nove tratamentos e quatro repetições. A unidade experimental foi composta por um canteiro com área total de 2,4 $\mathrm{m}^{2}$ (1,5 m de largura x 1,6 m de comprimento) e área útil de $1,6 \mathrm{~m}^{2}(1,0 \mathrm{~m}$ de largura x 1,6 m de comprimento), contendo duas fileiras de oito plantas, espaçadas de $0,60 \mathrm{~m}$ entre elas e 0,20 m entre plantas, resultando na população de 66.000 plantas ha-1.

As mudas para o plantio foram rebentos classificados pela massa nas classes $1(11,22 \mathrm{~g})$, $2(11,32 \mathrm{~g}), 3(11,55 \mathrm{~g})$ e $4(14,75 \mathrm{~g})$, sendo cada classe sorteada para fazer parte de uma repetição. No dia anterior ao plantio, as mudas foram selecionadas, imersas nas soluções conforme os tratamentos e deixadas sobre mesas, em ambiente protegido, em temperatura ambiente, para secar. Para melhorar a aderência foi utilizado o espalhante-adesivo Cittowett $\AA$, na dose de 40 $\mathrm{mL}$ para 100 litros de água. No dia de plantio, os rebentos foram cortados horizontalmente na parte basal, colocados no fundo dos sulcos, com os ápices para cima e cobertos com solo (HEREDIA ZÁRATE et al., 2008). 


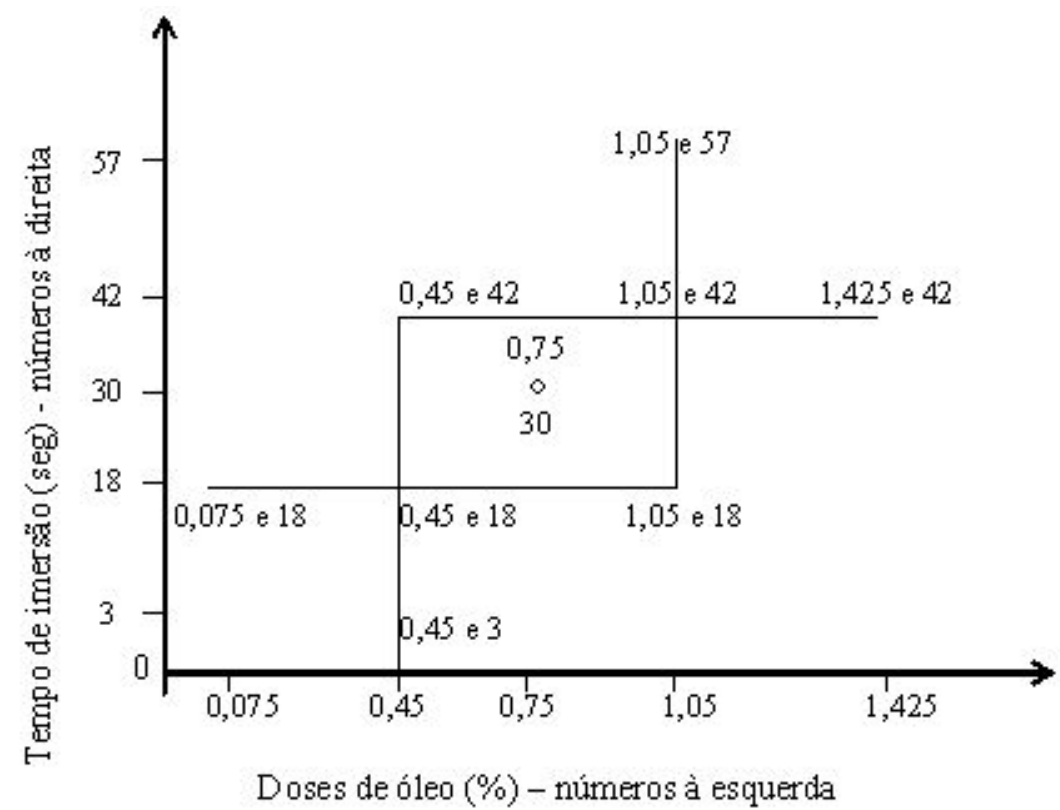

Figura 1. Tratamentos determinados, como resultado das combinações de cinco doses de óleo de eucalipto e cinco tempos de imersão, utilizando-se a matriz experimental Plan Puebla III.

Fonte: Turrent e Laird (1975).

Não foi feita calagem para correção do solo nem adubação. As irrigações foram feitas utilizando o sistema de aspersão, sendo que na fase inicial, até as plantas apresentarem em torno de $10 \mathrm{~cm}$ de altura, os turnos de rega foram diários e, posteriormente, a cada dois dias. As capinas foram feitas com enxada, entre os canteiros, e manualmente, dentro dos canteiros.

Durante o ciclo de cultivo das plantas, avaliaram-se o estande inicial ou porcentagem de pegamento das mudas, aos 76 dias após o plantio (DAP), o estande final no dia da colheita, aos 229 DAP, a severidade e a incidência de doenças na parte aérea das plantas, aos 76, 110 e 147 DAP, e a incidência de doenças no solo, entre 110 e 219 DAP. A caracterização dos patógenos foi realizada nos Laboratórios de Fitopatologia da UFGD e de Microbiologia da UEM. A severidade das doenças foi determinada visualmente, utilizandose escala de zero (sem sintoma de infecção) a 5 (planta morta).
A colheita foi realizada aos 229 DAP, quando as plantas apresentavam como indicativo do ponto de colheita o amarelecimento e secamento de mais de $50 \%$ das folhas externas das plantas (HEREDIA ZÁRATE et al., 2008). Na colheita, foram avaliadas as produções de massas frescas e secas de folhas, rebentos, coroas e raízes comerciais (maiores que $30 \mathrm{~g}$ ) e não-comerciais (menores que $30 \mathrm{~g}$ ).

Para estimar as superfícies de resposta, foram ajustados os modelos quadrático e quadrático base raiz quadrada às médias por tratamento. Cada componente dos modelos foi testado até $5 \%$ de probabilidade, pelo teste $\mathrm{F}$, tendo sido utilizado o quadrado médio do erro experimental da matriz. Cada efeito individual do modelo escolhido foi testado até o nível de $5 \%$, pelo teste $\mathrm{F}$, corrigido em função do erro experimental, usando t calculado pelo programa estatístico SAEG (ALVAREZ VENEGAS, 1991; RIBEIRO JÚNIOR, 2001). As notas de severidade das doenças no campo foram transformadas a índice 
de intensidade de doença mediante uso da equação de Mckinney e posterior uso da fórmula $\operatorname{arcsen} \sqrt{x}($ CZERMAINSKI, 1999).

\section{Resultados e Discussão}

Os estandes iniciais (Figura 2A) e finais (Figura 2B) da mandioquinha-salsa, determinados aos 76 e 229 dias após o plantio, respectivamente, foram influenciados significativamente pela interação doses de óleo de eucalipto e tempos de imersão das mudas na solução. Os maiores estandes iniciais e finais foram obtidos com as doses de óleo menores que $1,0 \%$ e tempos de imersão variando entre 3 s e 42 s. O máximo estande inicial foi de 66.820 plantas $\mathrm{ha}^{-1}$, sob dose de óleo de eucalipto de $0,16 \%$ e tempo de imersão de 18,9 s e o final foi de 48.320 plantas $\mathrm{ha}^{-1}$, sob dose de óleo de eucalipto de $0,099 \%$ e tempo de imersão de 13,0 s. Os menores estandes inicial (36.100 plantas ha $\left.^{-1}\right)$ e final (16.500 plantas $\mathrm{ha}^{-1}$ ) foram com o tratamento $1,425 \% / 42 \mathrm{~s}$. As menores percentagens de pegamento das mudas e de sobrevivência das plantas tratadas com as maiores doses de óleo de eucalipto mostram que houve modificações na plasticidade fisiológica da planta para adaptar-se às condições ambientais (GRACIANO et al., 2007).

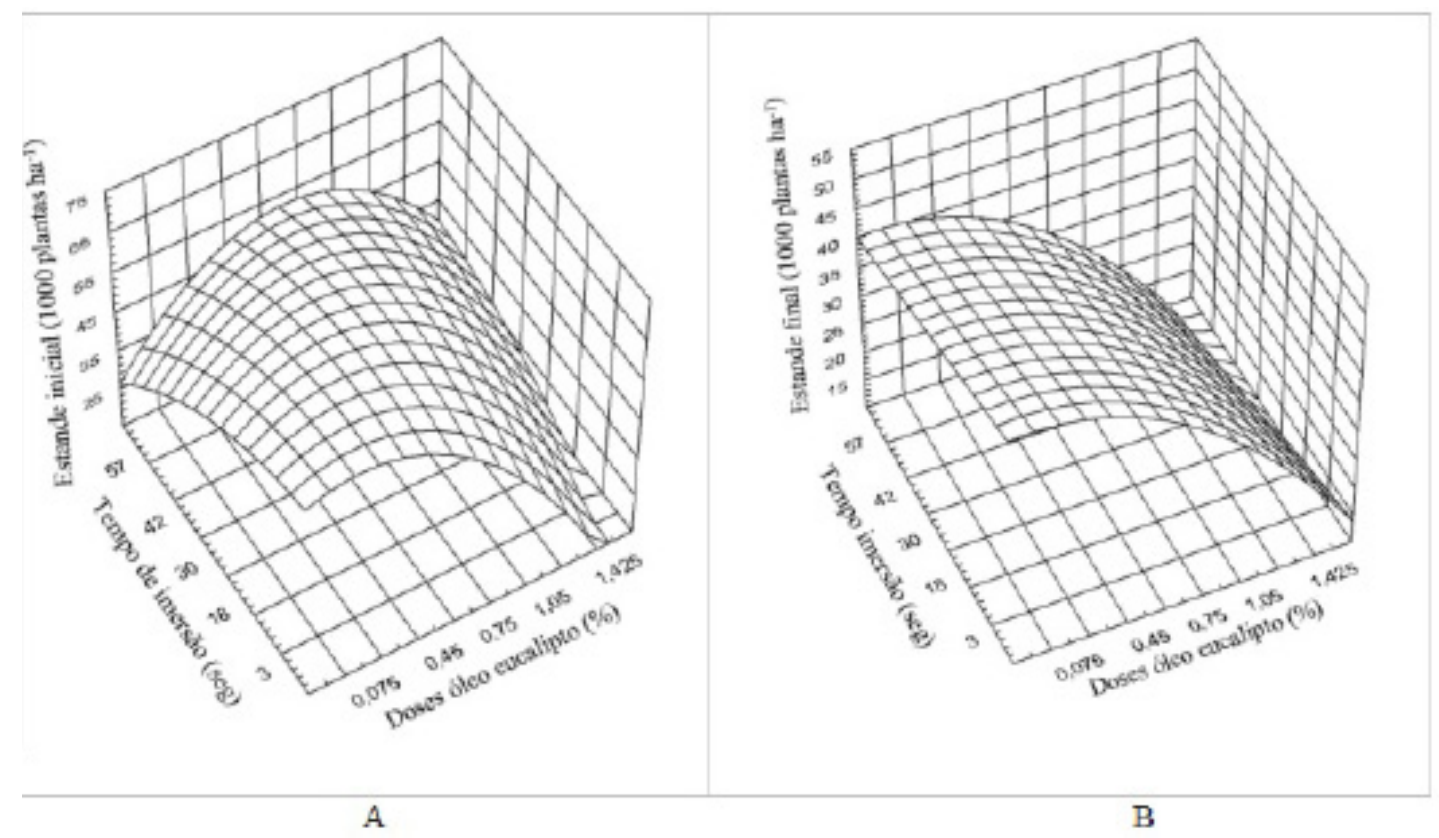

Estande inicial

$\mathrm{A}-\hat{\mathrm{y}}=66,324+8,22926 \mathrm{D}-0,10553 \mathrm{~T}-29,9327 * * \mathrm{D}^{2}-0,0054857 * \mathrm{~T}^{2}+0,548174 * * \mathrm{DT} ; \mathrm{R}^{2}=0,99$

Estande final

$\mathrm{B}-\hat{\mathrm{y}}=48,701-2,45919 * * \mathrm{D}-0,130652 * \mathrm{~T}-12,2992 * * \mathrm{D}^{2} ; \mathrm{R}^{2}=0,94$

Figura 2. Estandes inicial e final de plantas de mandioquinha-salsa 'Amarela de Carandai', propagadas com mudas desinfectadas com diferentes doses de óleo de eucalipto e tempos de imersão.

Fonte: Alvarez Venegas (1991); Ribeiro Júnior (2001). 
A interação dose de óleo de eucalipto e tempo de imersão das mudas influenciaram significativamente as produções de massa fresca de folhas $\left(2,49 \mathrm{t} \mathrm{ha}^{-1}\right.$, sob $0,30 \%$ e $0,02 \mathrm{~s}$ ) (Figura $3 \mathrm{~A})$, de rebentos $(2,32$ $\mathrm{t} \mathrm{ha}^{-1}$, sob $0,38 \%$ e 33,26 s) (Figura 3B) e de raiz comercial $\left(3,32 \mathrm{t} \mathrm{ha}^{-1}\right.$, sob $0,44 \%$ e $39,21 \mathrm{~s}$ ) (Figura 3D) e as massas secas de coroa $\left(0,38 \mathrm{tha}^{-1}\right.$, sob $0,76 \%$ e $36,57 \mathrm{~s}$ ) (Figura 4C) e de raiz comercial $(0,65 \mathrm{t}$ ha $^{-1}$, sob $0,20 \%$ e 17,9 s ) (Figura 4D). As doses de óleo de eucalipto influenciaram significativamente as produções de massas frescas de coroas (3,02 $\mathrm{t} \mathrm{ha}^{-}$ ${ }^{1}$, sob $0,075 \%$ ) (Figura $3 \mathrm{C}$ ) e de raiz não-comercial $\left(1,87 \mathrm{t} \mathrm{ha}^{-1}\right.$, sob 0,07\%) (Figura 3E) e as massas secas de folhas $\left(0,35 \mathrm{t} \mathrm{ha}^{-1}\right.$, sob $\left.0,53 \%\right)$ (Figura $\left.4 \mathrm{~A}\right)$, de rebentos $\left(0,44 \mathrm{t} \mathrm{ha}^{-1}\right.$, sob 0,075\% ) (Figura 4B) e de raiz não-comercial $\left(0,36 \mathrm{t} \mathrm{ha}^{-1}\right.$, sob $\left.0,11 \%\right)$ (Figura $4 \mathrm{E})$. Esses resultados demonstram que os sistemas vegetais têm mecanismos de autoregulação, baseados na capacidade de adaptação do organismo individual e das populações ou no equilíbrio das relações de interferência (HEREDIA ZÁRATE et al., 2008). Portanto, a produção de raízes de mandioquinha-salsa parece depender, além de fatores que favoreçam o crescimento da parte aérea, de fatores que proporcionem o desenvolvimento harmônico entre partes aérea e subterrânea (LEBLANC et al., 2008).

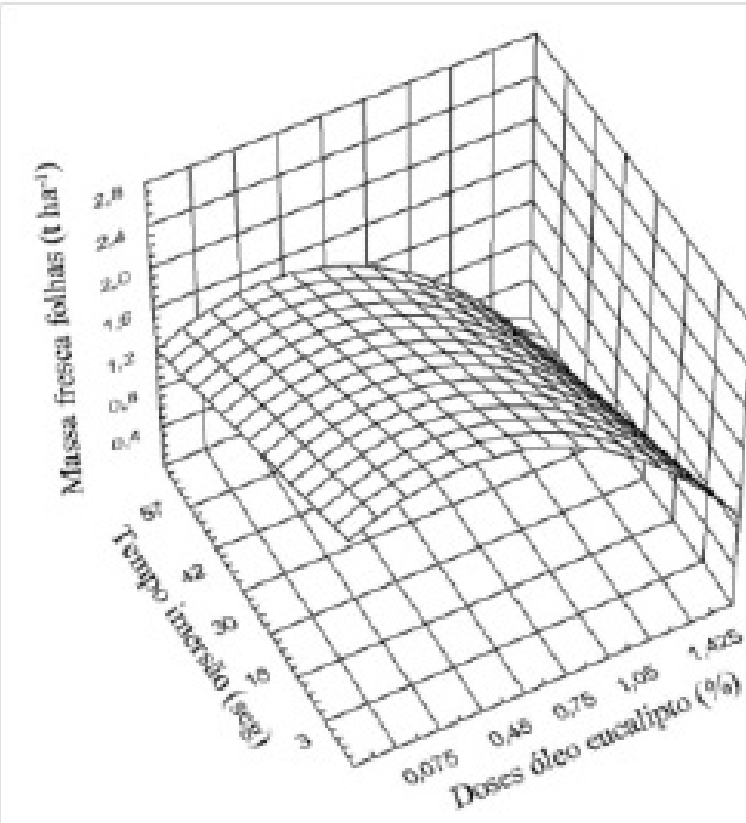

A

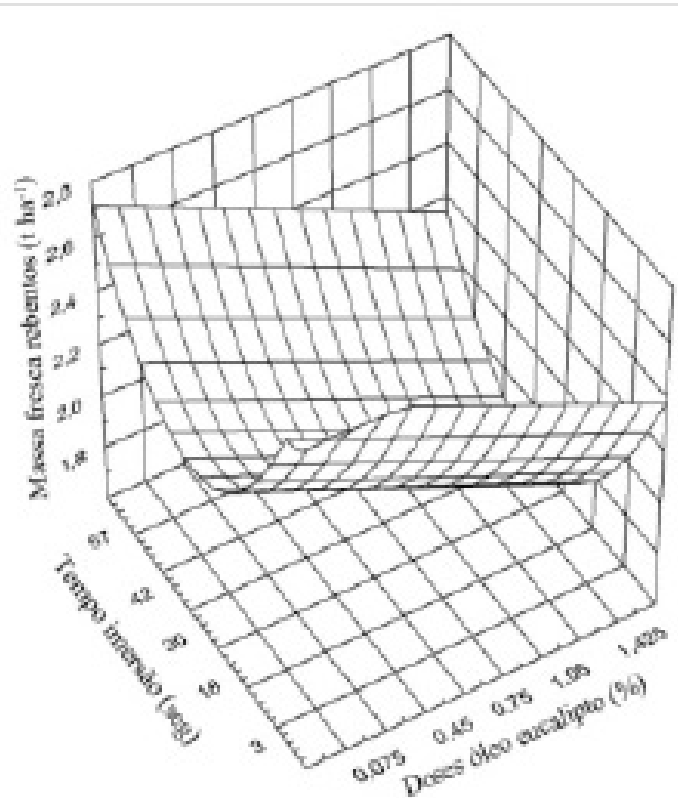

B

Massa fresca de folhas

$\mathrm{A}-\hat{\mathrm{y}}=2,39553+0,594292 * * \mathrm{D}-0,0161377 * * \mathrm{~T}-0,977022 * * \mathrm{D}^{2} ; \mathrm{R}^{2}=0,82$

Massa fresca de rebentos

$\mathrm{B}-\hat{\mathrm{y}}=2,70371+1,02248 * * \mathrm{D}-0,034544 \mathrm{~T}-1,34343^{* *} \mathrm{D}^{2}+0,000519336 * * \mathrm{~T}^{2} ; \mathrm{R}^{2}=0,82$ 


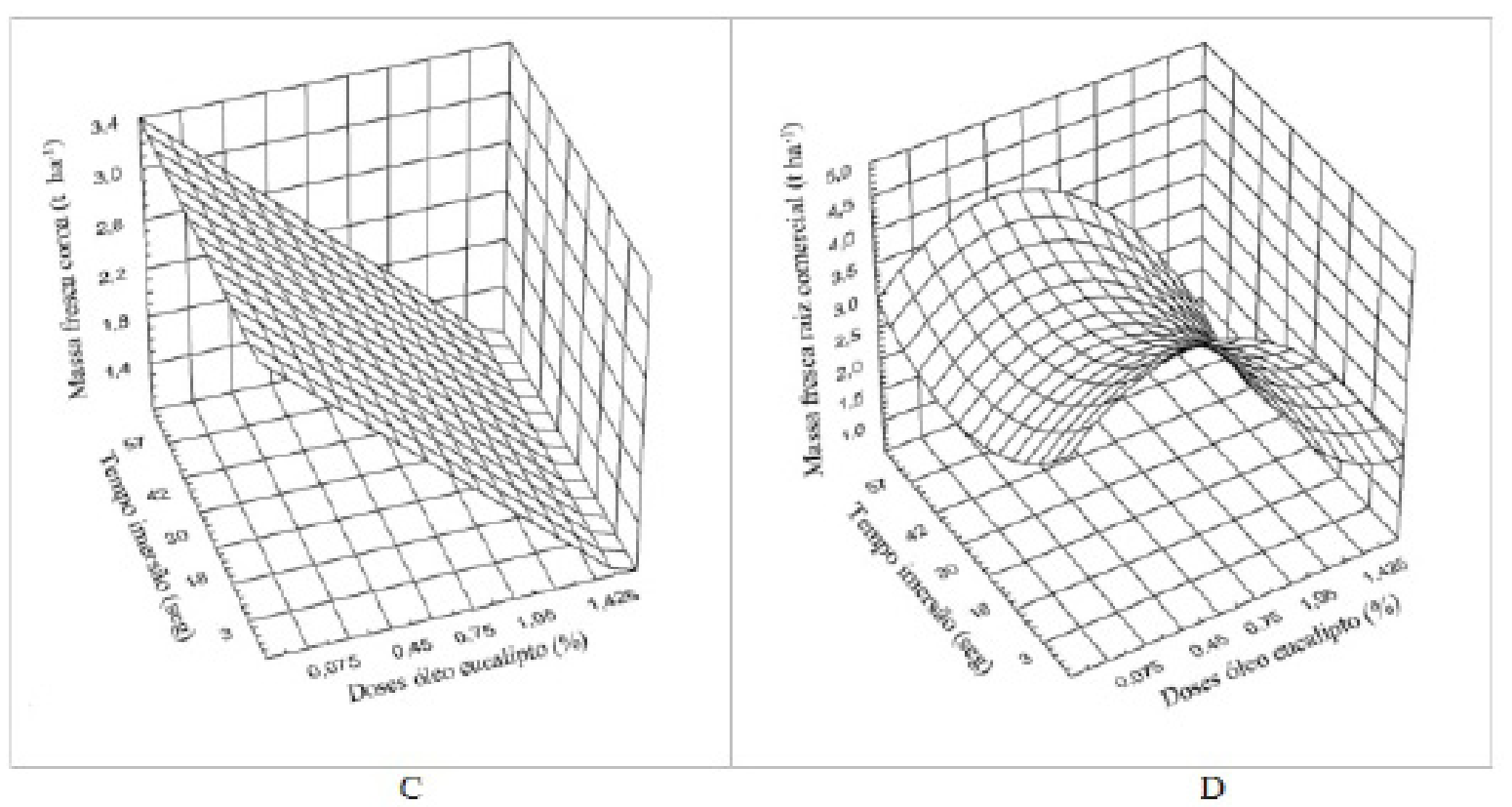

Massa fresca de coroa

$\mathrm{C}-\hat{\mathrm{y}}=3,12584-1,39742 \mathrm{D} ; \mathrm{R}^{2}=0,83$

Massa fresca raízes comerciais

$\hat{\mathrm{y}}=4,08002+1,9501188 \mathrm{D}-0,06037773 \mathrm{~T}-2,22822 * \mathrm{D}^{2}+0,000769766^{*} \mathrm{~T}^{2} ; \mathrm{R}^{2}=0,82$

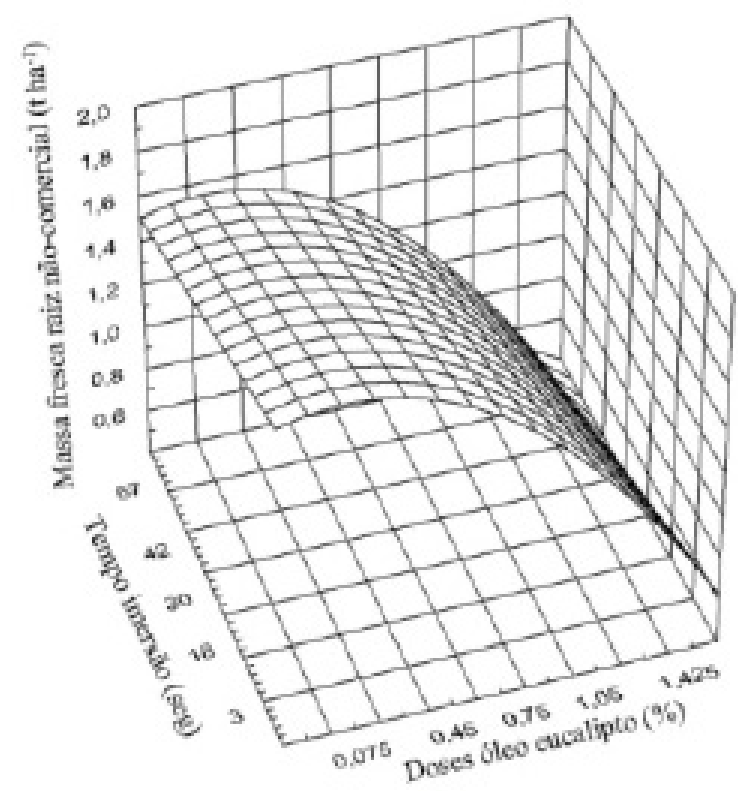

E

Massa fresca de raízes não-comerciais

$E-\hat{y}=1,86641+0,0763018 * * D-0,0049808 T-0,543143 * * D^{2} ; R^{2}=0,78$

Figura 3. Massa fresca de folhas (A), rebentos (B), coroas (C), raízes comerciais (D) e raízes não comerciais (E) de plantas de mandioquinha-salsa 'Amarela de Carandai', propagadas com mudas desinfectadas com diferentes doses de óleo de eucalipto e tempos de imersão.

Fonte: Alvarez Venegas (1991); Ribeiro Júnior (2001). 


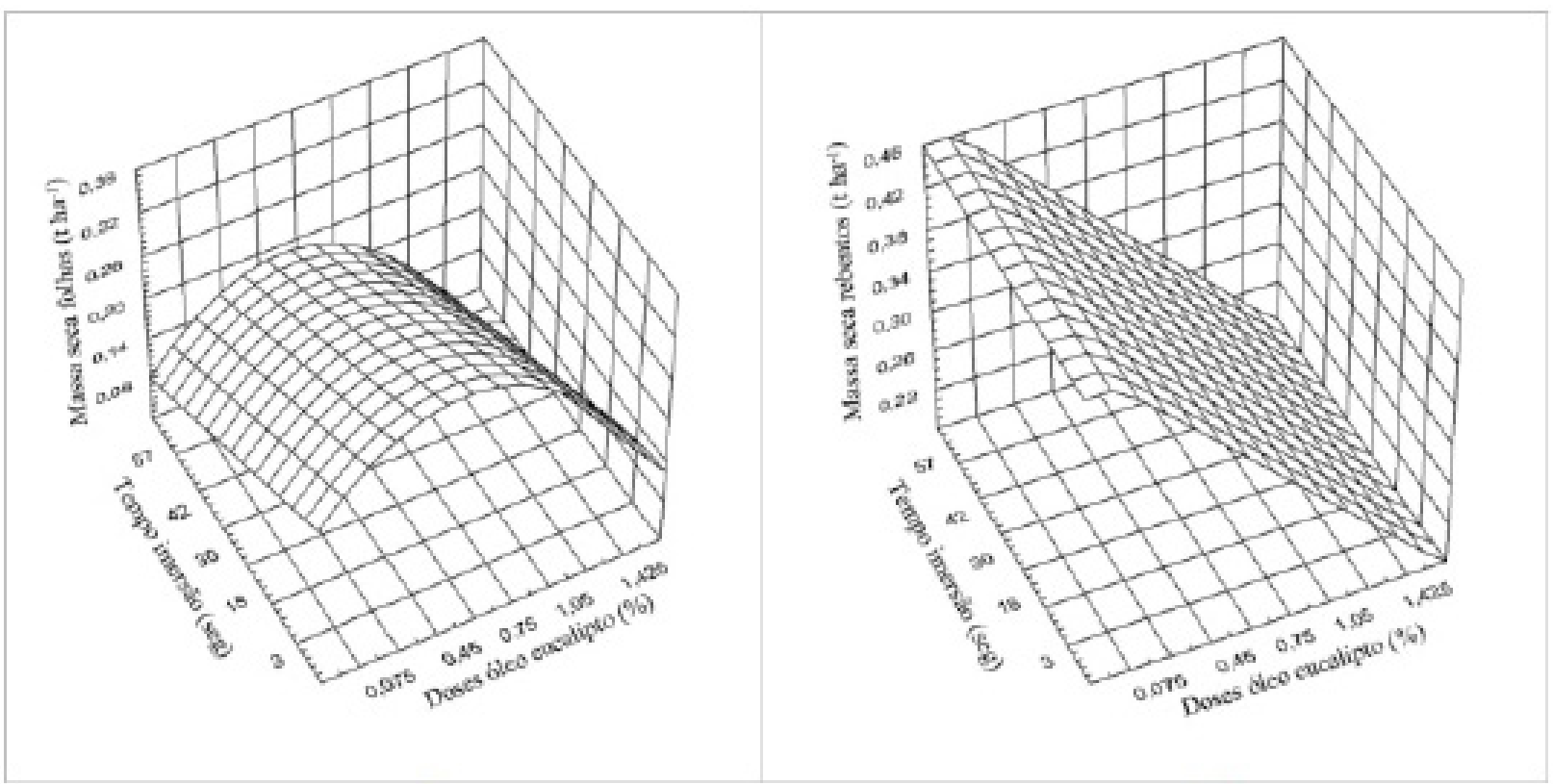

A

B

Massa seca de folhas

$\mathrm{A}-\hat{\mathrm{y}}=0,288265+0,213588^{* *} \mathrm{D}-0,00240945^{*} \mathrm{~T}-0,201965 * * \mathrm{D}^{2} ; \mathrm{R}^{2}=0,67$

Massa seca de rebentos

$\mathrm{B}-\hat{\mathrm{y}}=0,453902-0,17261^{* *} \mathrm{D} ; \mathrm{R}^{2}=0,58$

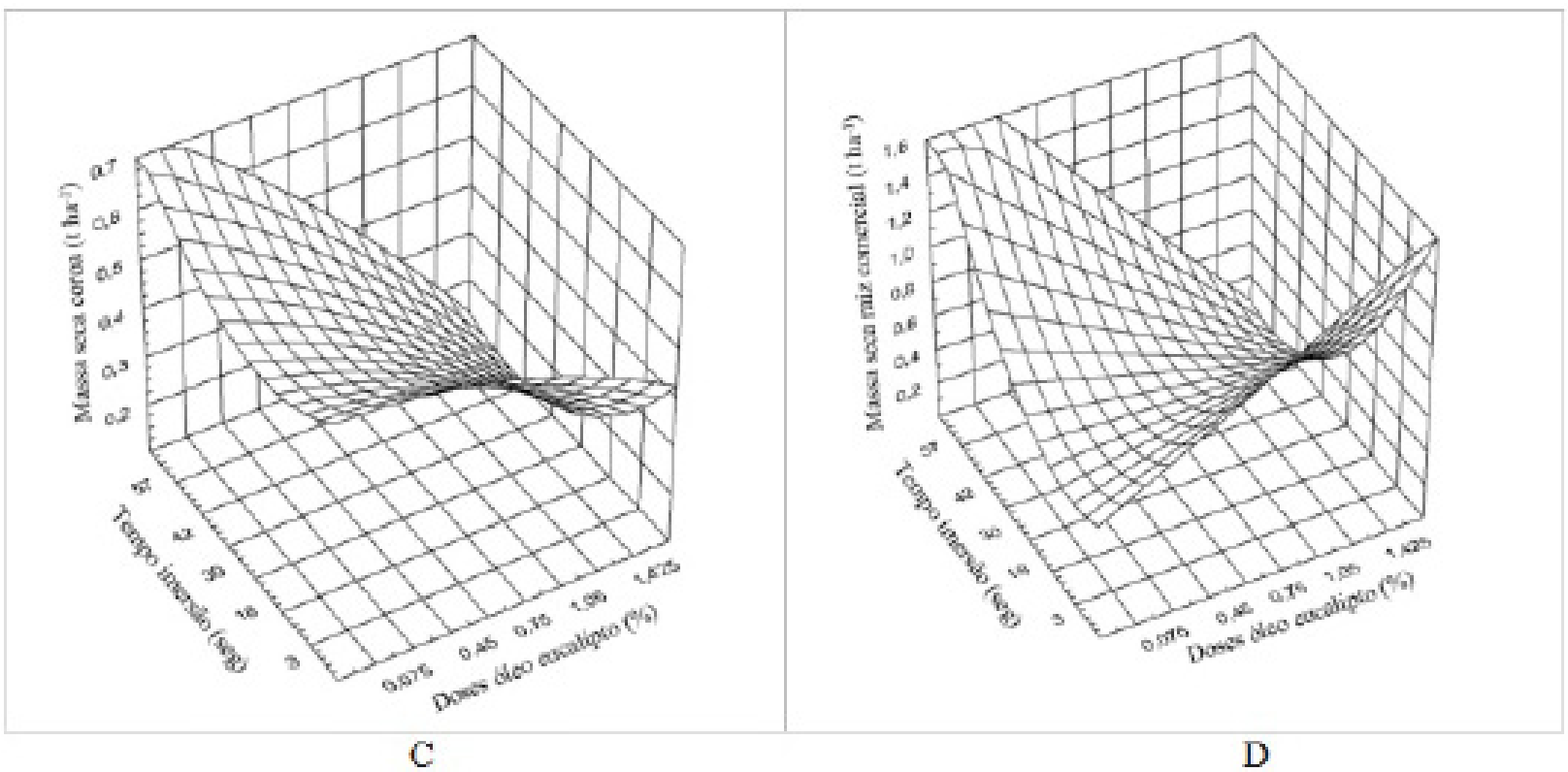

Massa seca de coroa

$\mathrm{C}-\hat{\mathrm{y}}=0,588848-0,045241 \mathrm{D}-0,00537531 \mathrm{~T}-0,0585475 \mathrm{D}^{2}+0,0001087 \mathrm{~T}^{2}-0,0033975 \mathrm{DT}$; $\mathrm{R}^{2}=0,58$

Massa seca de raízes comerciais

$\mathrm{D}-\hat{\mathrm{y}}=0,698426+0,417382 * * \mathrm{D}-0,010454 \mathrm{~T}+0,00705186 * \mathrm{D}^{2}+0,000423213 \mathrm{~T}^{2}-0,0234876 * \mathrm{DT} ; \mathrm{R}^{2}=$ 0,82 


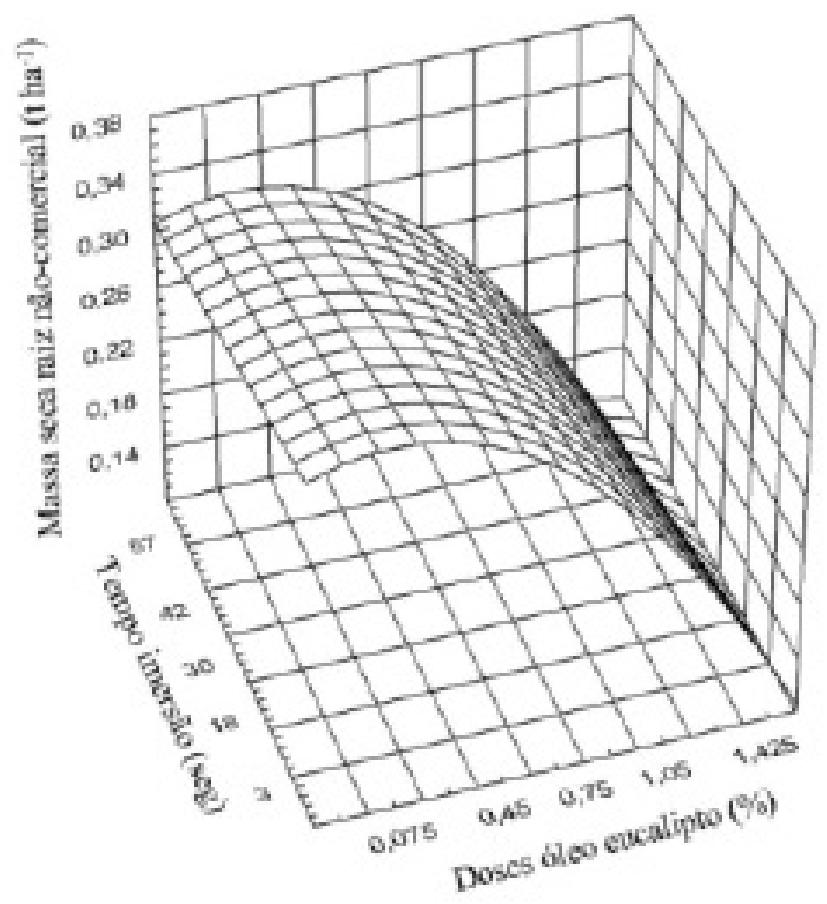

E

Massa seca de raízes não-comerciais

$$
\hat{y}=0,355068+0,0237492 \mathrm{D}-0,000618836 \mathrm{~T}-0,113427 \mathrm{D}^{2} ; \mathrm{R}^{2}=0,73
$$

Figura 4. Massa seca de folhas (A), rebentos (B), coroas (C), raízes comerciais (D) e raízes não comerciais (E) de plantas de mandioquinha-salsa 'Amarela de Carandai', propagadas com mudas desinfectadas com diferentes doses de óleo de eucalipto e tempos de imersão.

Fonte: Alvarez Venegas (1991); Ribeiro Júnior (2001).

No geral, o tratamento $1,425 \%$ de óleo de eucalipto e $42 \mathrm{~s}$ de tempo de imersão das mudas induziram as menores produções de massas frescas e secas. Essa resposta relaciona-se com a citação de Kuhn (2007), de que as plantas que investem seus recursos para se defenderem na ausência de patógenos arcarão com custos que refletirão na produtividade, uma vez que, as alterações metabólicas que levam à resistência têm um custo adaptativo associado, o qual pode pesar mais que o benefício.

As produções de raízes comerciais e nãocomerciais obtidas neste experimento são baixas, quando comparadas com as relatadas por Heredia Zárate et al. (2009) quando estudaram a produtividade da mandioquinha-salsa em função da densidade populacional e do tamanho das mudas utilizadas na propagação. Esses autores obtiveram produções de $11,61 \mathrm{t} \mathrm{ha}^{-1}$ e $5,80 \mathrm{t} \mathrm{ha} \mathrm{h}^{-1}$, respectivamente, nas plantas dos tratamentos mudas grandes e três fileiras de plantas no canteiro, na colheita aos 211 DAP, e de 14,48 tha-1 e 5,92 $\mathrm{t} \mathrm{ha}^{-1}$, nas dos tratamentos mudas muito pequenas e duas fileiras de plantas e mudas pequenas e três fileiras de plantas, respectivamente, na colheita aos 239 DAP. Estas diferenças produtivas podem associarse ao cultivo em épocas diferentes, e que neste caso, as plantas tiveram que se desenvolver na maioria de meses mais quentes do ano (Figura 5), ao contrário do que seria o ideal, já que a mandioquinha-salsa é uma planta de origem andina e no Brasil é cultivada principalmente nas regiões serranas de Minas Gerais. 


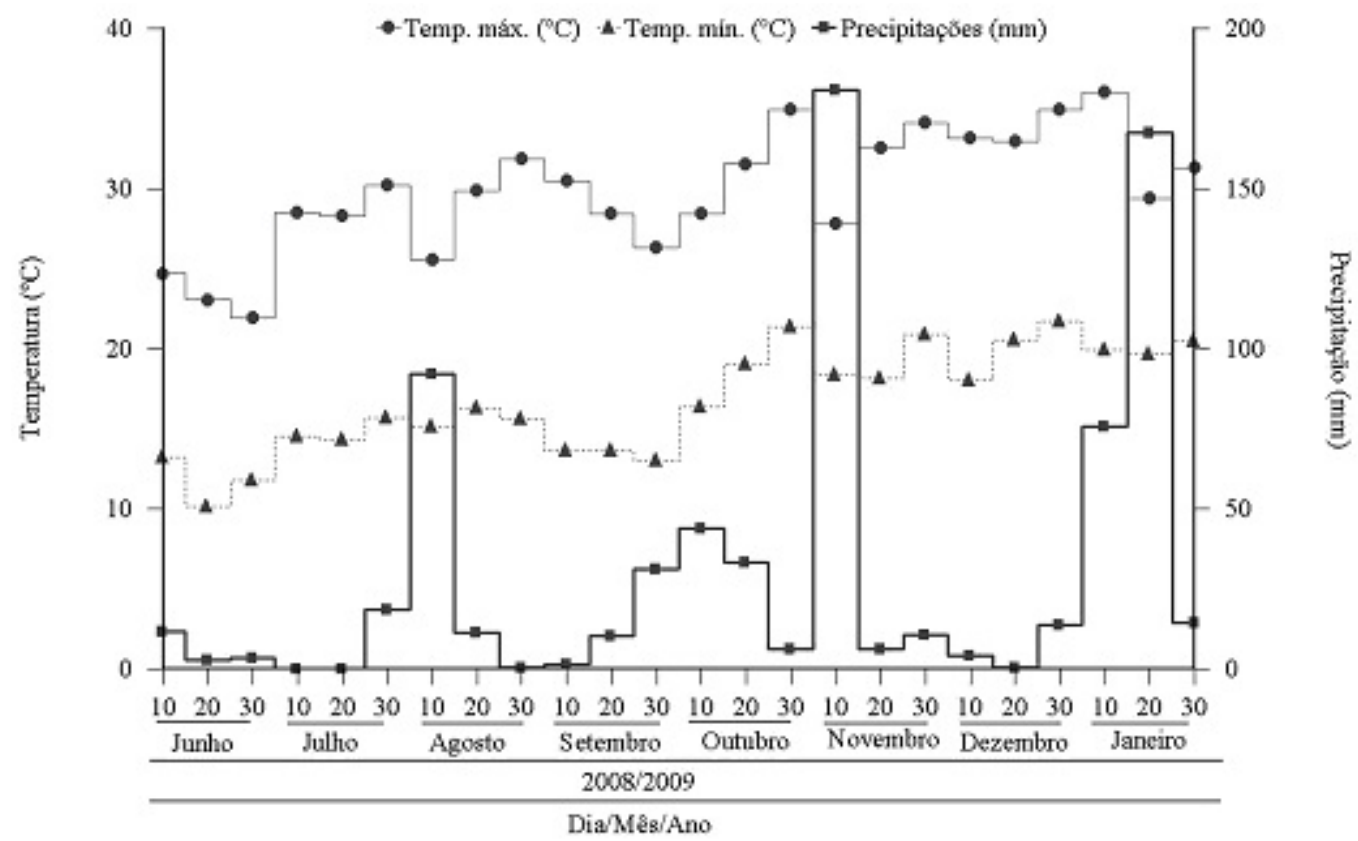

Figura 5. Temperaturas máximas e mínimas (médias por decêndio) e precipitação total na época de desenvolvimento do experimento, em Dourados-MS.

Fonte: Estação Meteorológica da Universidade Federal da Grande Dourados.

Foram observados sintomas de queima das folhas, nas avaliações aos 76, 110 e 146 DAP e de podridões das coroas e dos rebentos, entre 111 e 226 DAP. Os agentes patogênicos responsáveis pela queima das folhas foram Alternaria $s p$ e Septoria $s p$, apresentando-se associados e sem possibilidade de quantificação isoladamente. O índice de intensidade de doença $(\mathrm{C} . \mathrm{V}=0,93 \%)$ foi independente do tratamento (dose de óleo de eucalipto e do tempo de imersão das mudas na solução) com média ponderada de 0,82 , mas foi estatisticamente dependente da época de avaliação, com o maior valor aos 146 DAP $(0,83)$ e o menor aos 110 DAP $(0,80)$. Esses resultados podem ter relação com a provável produção pelas plantas de fitoalexinas, peroxidases e proteínas ou outros metabólitos secundários antimicrobianos, em resposta a estresses físicos, químicos ou biológicos, capazes de impedir ou reduzir a atividade de agentes patogênicos. Isso porque, na natureza, a resistência pode ser induzida pela interação das plantas com os microorganismos que as circundam (SCHWANESTRADA; STANGARLIN; CRUZ, 2000).
Emrelação às podridões das coroas e dos rebentos, o principal agente fitopatogênico foi Sclerotium $s p$ e a incidência foi influenciada pela interação do tratamento (dose de óleo de eucalipto e do tempo de imersão das mudas na solução) e da época de avaliação. Nas plantas do tratamento 1,05\%/42 s não foram detectadas infecções mas no tratamento $0,075 \% / 18 \mathrm{~s}$ as infecções chegaram a 5,16\%, que foi a máxima. Uma das possíveis explicações para a elevada variabilidade da efetividade da resistência induzida é que a mesma está sujeita a modulação por fatores ambientais, como o estresse hídrico ou nutricional. Além disso, alguns autores consideram que o uso da resistência induzida poderia interferir na composição, funcionamento e desempenho da comunidade do solo (KUHN, 2007).

\section{Conclusões}

A desinfecção das mudas de mandioquinhasalsa com óleo de eucalipto em doses menores que $0,5 \%$ e com imersão na solução em torno de $40 \mathrm{~s}$ proporcionaram menor incidência de doenças 
foliares e maior produção de raízes comerciais.

\section{Agradecimentos}

Ao CNPq, pelas bolsas concedidas; à FUNDECT-MS, pelo apoio financeiro e à UEM, pela oportunidade para realizar o Pós-doutorado. Ao Prof. Dr. Walber Luiz Gavassoni e ao Eng. Agr. Bruno C. Álvaro Pontim, da UFGD, pelo auxílio na identificação dos patógenos.

\section{Referências}

ALVAREZ VENEGAS, V. H. Avaliação da fertilidade do solo: superficies de resposta - modelos aproximativos para expressar a relação fator-resposta. Viçosa: UFV, 1991, $75 \mathrm{p}$.

AMARAL, M. F. Z. J.; BARA, M. T. F. Avaliação da atividade antifúngica de extratos de plantas sobre o crescimento de fitopatógenos. Revista Eletrônica de Farmácia, Goiânia, v. 2, n. 2, p. 5-8, 2005.

BRUNE, S.; GIORDANO, L. B.; LOPES, C. A.; MELO, P. E. Tratamento químico de mudas de mandioquinhasalsa. Horticultura Brasileira, Brasília, v. 14, n. 3, p. 207-210, 1996.

CZERMAINSKI, A. B. C. Generalização de um índice de intensidade de infecção em experimentos de avaliação de doenças de plantas. Pesquisa Agropecuária Brasileira, Brasília, v. 34, n. 9, p. 1545-1555, 1999.

EMPRESA BRASILEIRA DE PESQUISA AGROPECUÁRIA - EMBRAPA. Centro Nacional de Pesquisa de Solos. Sistema brasileiro de classificação de solos. Brasília: Embrapa Produção de Informação; Rio de Janeiro: Embrapa Solos. 1999. 412 p.

GRACIANO, J. D.; HEREDIA ZÁRATE, N. A.; VIEIRA, M. C.; ROSA, Y. B. C. J.; SEDIYAMA, M. A. N. Espaçamentos entre fileiras e entre plantas na produção da mandioquinha-salsa 'Branca'. Ciência e Agrotecnologia, Lavras, v. 31, n. 6, p. 1688-1695, 2007.

GRANATE, M. J.; SEDIYAMA, M. A. N.; PUIATTI, M. Batata-baroa ou mandioquinha-salsa (Arracacia xanthorrhiza Banc.). In: PAULA JÚNIOR, T. J.; VENZON, M. (Coord.). 101 culturas: manual de tecnologias agrícolas. Belo Horizonte: EPAMIG, 2007. p. $137-142$.

HEREDIA ZÁRATE, N. A.; VIEIRA, M. C.; GRACIANO, J. D.; FIGUEIREDO, P. G.; BLANS, N.
B.; CURIONI, B. M. Produtividade de mandioquinhasalsa sob diferentes densidades de plantio e tamanho das mudas. Ciência Agrotecnologia, Lavras, v. 33, n. 1, p. 139-143, 2009.

HEREDIA ZÁRATE, N. A.; VIEIRA, M. C.; RECH, J.; QUAST, A.; PONTIM, B. C. A.; GASSI, R. P. Yield and gross income of arracacha in monocrop and intercropping with the Japanese bunching onion and parsley. Horticultura Brasileira, Brasília, v. 26, n. 1, p. 277-281, 2008.

KUHN, O. J. Indução de resistência em feijoeiro (Phaseolus vulgaris) por acinbezolar-S-metil e Bacillus cereus: aspectos fisiológicos, bioquímicos e parâmetros de crescimento e produção. 2007. Tese (Doutorado em Agronomia) - Universidade de São Paulo, Piracicaba.

LEBLANC, R. E. G.; PUIATTI, M.; SEDIYAMA, M. A. N.; FINGER, F. L.; MIRANDA, G. V. Influência do pré-enraizamento e de tipos de mudas sobre a população, crescimento e produção da mandioquinha-salsa "Roxa de Viçosa". Revista Ceres, Viçosa, v. 55, n. 1, p. 74-82, 2008.

LOPES, C.; HENZ, G. P. Doenças da mandioquinhasalsa. Informe Agropecuário, Belo Horizonte, v. 19, n. 190, p. 49-51, 1997.

RIBEIRO JÚNIOR, J. I. Análise estatística no SAEG. Viçosa: UFV. 2001. 301 p.

SALGADO, A. P. S.; CARDOSOS, M. G.; SOUZA, P. E.; SOUZA, J. A.; ABREU, C. M. P.; PINTO, J. E. B. Avaliação da atividade fungitóxica de óleos essenciais de folhas de Eucalyptus sobre Fusarium oxysporum, Botrytis cinerea e Bipolaris sorokiniana. Ciência $e$ Agrotecnologia, Lavras, v. 27, n. 2, p. 249-254, 2003.

SCHWAN-ESTRADA, K. R. F.; STANGARLIN, J. R.; CRUZ, M. E. S. Uso de extratos vegetais no controle de fungos fitopatogênicos. Floresta, Curitiba, v. 30, n. 1/2, p. 129-138, 2000.

TURRENT, A.; LAIRD, R. J. La matriz experimental Plan Puebla, para ensayos sobre prácticas de praducción de cultivos. Agrociencia, Texcoco, v. 19, p. 117-143, 1975.

VIEIRA, M. C.; HEREDIA ZÁRATE, N. A.; GOMES, H. E. Produção de mandioquinha-salsa em função da desinfecção de mudas e da cobertura do solo com cama de frango semidecomposta. Ciência e Agrotecnologia, Lavras, p. 1465-1470, 2002. Edição Especial. 
